\title{
TO THE LIMIT
}

More people are surviving to older ages than ever before, pushing life expectancy from birth to unprecedented highs. Further gains will require tackling age-related conditions, across the world, with ramifications for society as a whole. By Tony Scully.

\section{BORN \\ SURVIVORS}

Over the past 150 years, modern medicine and improved standards of living have increased life expectancy at birth by roughly 3 months per year. This graph plots women in several industrialized countries, but this trend is also true for men, and most of the world is following behind.

For humanity to continue to extend life expectancy, the rates of mortality in the oldest age groups must decline the most. This will only be achieved if the biggest killers - cancer, heart disease, stroke and Alzheimer's disease - are consigned to the past. But this will be tough given the rising levels of obesity and diabetes.

Another strategy to prolong life might be to slow the ageing process itself (see 'Live long and prosper', page S18).

CONTRIBUTION TO RISE IN LIFE EXPECTANCY AT BIRTH

$80+$ years

65-79 years

15-64 years

$0-14$ years

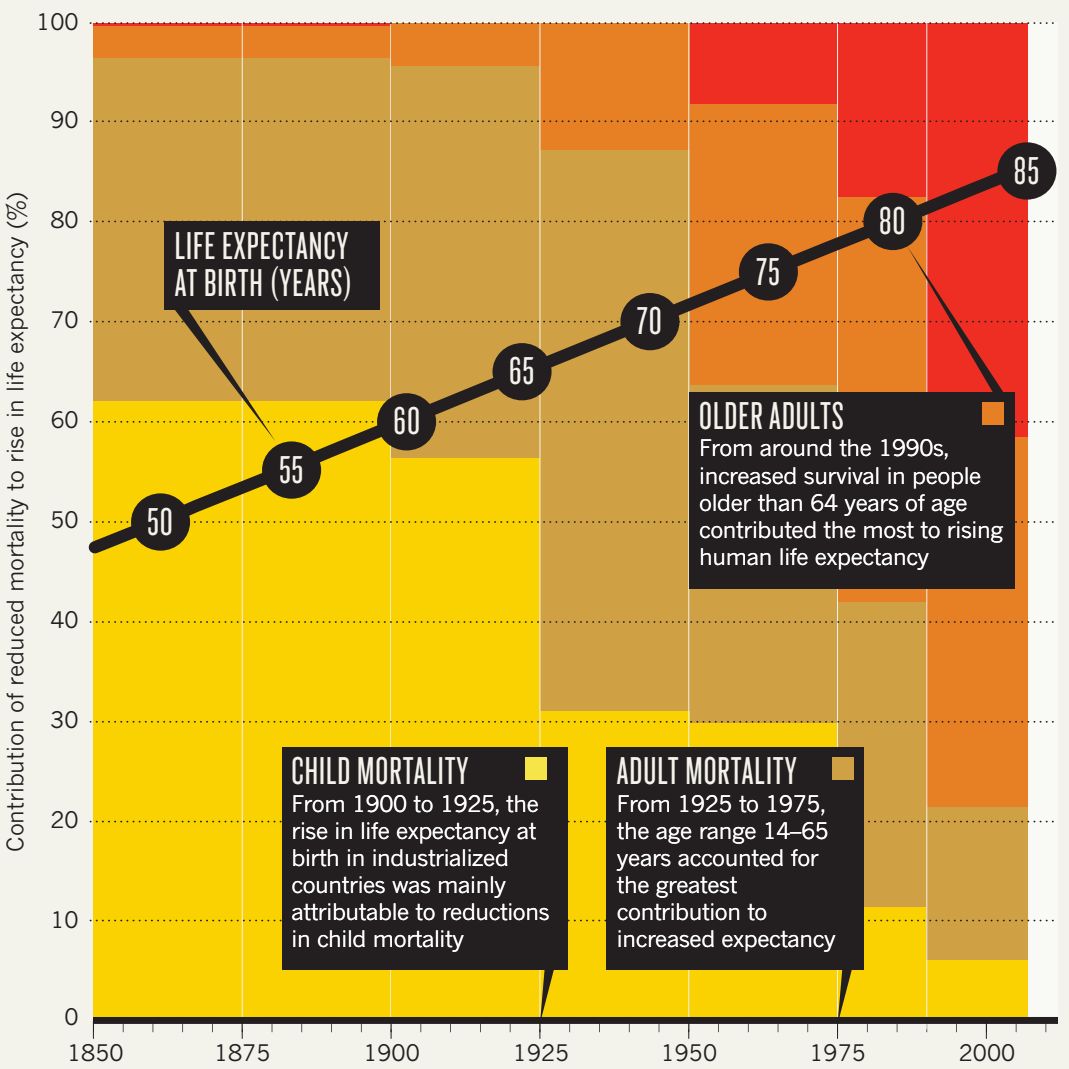

95

OLDEST

ADULTS

Future gain

will depend

on beating

the biggest

age-related killers

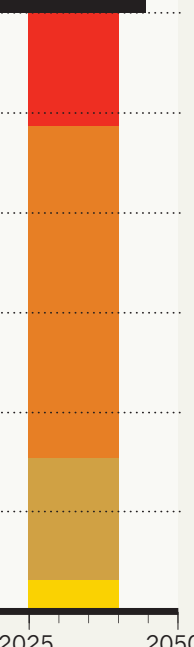

$2025-2050$

\section{THE COMING}

\section{OF AGE}

A survey in England asked over 10,000 people aged 50 years and older to report their health status and any limitations with independent living. The survey found that the prevalence of health problems increases with age while people become increasingly dependent on healthcare and community support to survive.

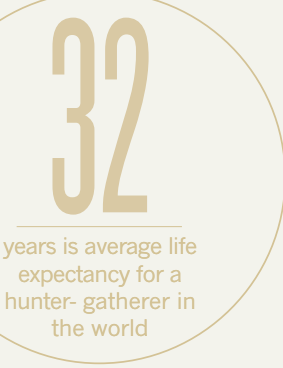

50

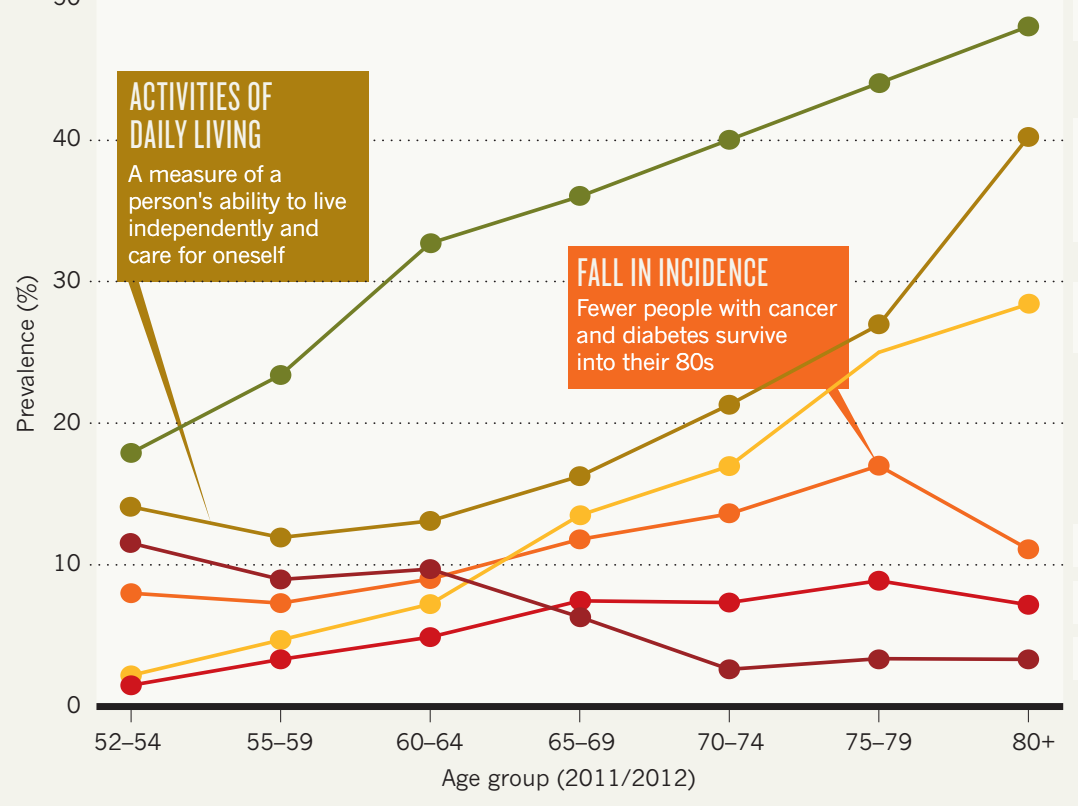

mpairment to one or more activities of daily living

Coronary heart disease

Diabetes Cancer Depression 


\section{LIFE EXPECTANCY AT 60 YEARS OF AGE}

A better indicator of the prospects of elderly people than life expectancy from birth, a 60-year-old person living in one of the least developed regions is still expected to reach 70 years of age and a person living in a developed country has a fair chance of reaching 90 years. The global population of people aged 60 years and older will more than double, from 542 million in 1995 to about 1.2 billion in 2025 .

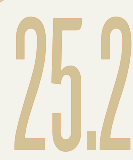

years added to life expectancy for people iving in less developed countries since
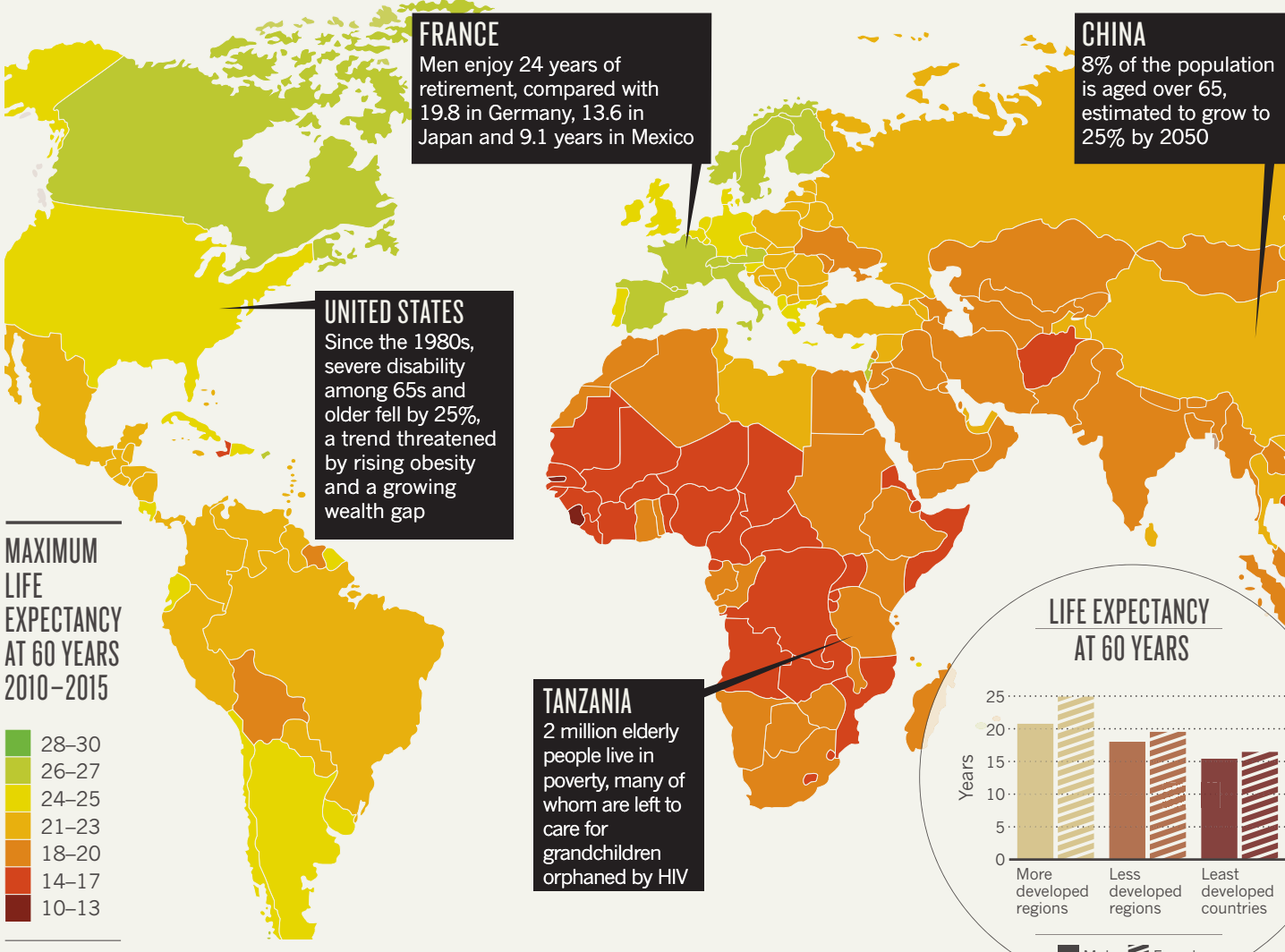